\title{
Kite String Injury Causing Digital Subtotal Amputation
}

\author{
Kshiteej Dhull ${ }^{1}$ \\ Deepti Gupta ${ }^{1}$ \\ ${ }^{1}$ Department of Burns, Plastic and Maxillofacial Surgery, VMMC and
Safdarjung Hospital, New Delhi, India \\ Indian J Plast Surg 2022;55:115-116.
}

\author{
Nupur Aggarwal1 ${ }^{10}$
}

Kite flying, although a leisure sport, is becoming increasingly competitive. The recently introduced Chinese thread or killer manja, made of nonbiodegradable synthetic fibers coated with metal dust, is tough and hazardous. ${ }^{1}$ A wide range of possible injuries can be sustained with a kite string, from minor lacerations to fatal injuries being reported. ${ }^{2,3}$ We write this letter to emphasize the need for timely intervention, even in seemingly innocuous injuries due to kite string.

Recently, two patients presented to us with digital injury, sustained on account of the kite string. A 23-year-old boy with a broken kite string encircling his right little finger (-Fig. 1). Another 19-year-old boy suffered a circumferential laceration of the right ring finger while flying a kite. Both presented to us within 6 hours of injury and were found to have type 1 subtotal digital amputation (Beimer's classifica-

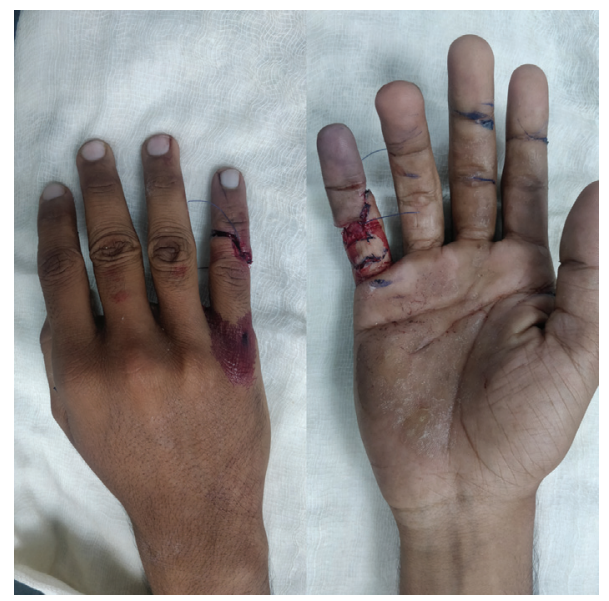

Fig. 1 Dorsal and ventral aspect of right hand with an oblique circumferential laceration of the little finger. The broken kite string is seen encircling the middle phalanx of the injured finger.

published online

February 12, 2022
DOI https://doi.org/ 10.1055/s-0041-1740086. ISSN 0970-0358.
Address for correspondence Deepti Guptam, MCh (Plastic Surgery), B-38, Derawal Nagar, Delhi-110009, India (e-mail: Deepti2611@gmail.com).

tion), with maintenance of only bony continuity. On exploration, the digital flexor, extensor tendons, and both neurovascular bundles were found to be transected. One digital artery and two dorsal veins were repaired under microscope, using $16 \mathrm{x}$ magnification, with 10-0 nylon sutures. The digital nerves and tendons were repaired, and a dorsal blocking splint was applied.

Early active motion rehabilitation protocol was followed. No adverse events were noted on regular clinical monitoring, and both patients were discharged on seventh postoperative day. On final evaluation at 3 months ( - Fig. 2 ), both patients showed good functional recovery according to disabilities of the arm, shoulder and hand (DASH) assessment. Two-point discrimination at fingertip was $6 \mathrm{~mm}$ and $8 \mathrm{~mm}$ in cases 1 and 2 , respectively.

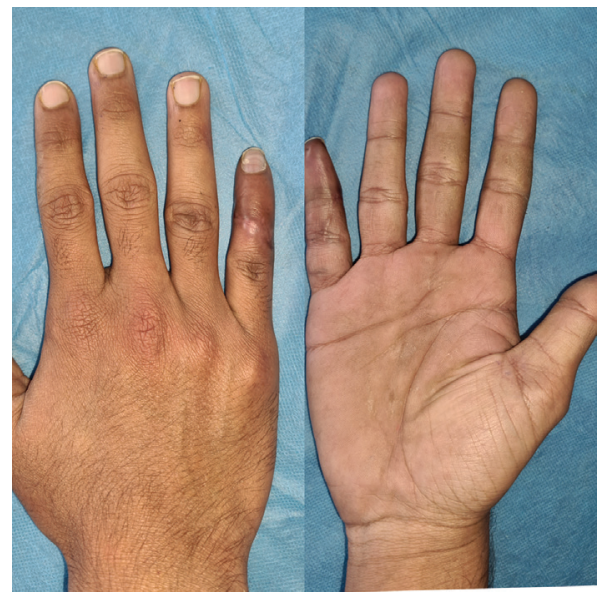

Fig. 2 Three month follow-up after repair of tendons and neurovascular structures. (c) 2022. Association of Plastic Surgeons of India. All rights reserved. This is an open access article published by Thieme under the terms of the Creative Commons Attribution-NonDerivative-NonCommercial-License, permitting copying and reproduction so long as the original work is given appropriate credit. Contents may not be used for commercial purposes, or adapted, remixed, transformed or built upon. (https://creativecommons.org/ licenses/by-nc-nd/4.0/)

Thieme Medical and Scientific Publishers Pvt. Ltd., A-12, 2nd Floor, Sector 2, Noida-201301 UP, India 
The successful outcome can be attributed to timely intervention, absence of a crush or avulsion component, involvement of a single digit, presence of a trained microsurgeon, and required infrastructure. As the digits have a warm ischemia time of 12 hours, it is important to reestablish circulation within this time period. ${ }^{4}$ Therefore, it is imperative to understand that digital kite string injuries can be extremely severe and can lead to adverse consequences in the absence of a timely and expert surgical intervention. A high index of suspicion and early exploration for underlying neurovascular injury are crucial in salvage and function of digits.

\section{References}

1 Muvalia G, Jamshed N, Sinha TP, Bhoi S. Kite-string injuries: a case series. Int J Crit Illn Inj Sci 2019;9(03):147-150

2 Prajapati C, Agrawal A, Atha R, Suri MP, Sachde JP, Shaikh MF. Study of kite string injuries in Western India. Int J Inj Contr Saf Promot 2017;24(01):136-139

3 Reddy JS, Pandey A, Chaudhary L, Kumar V, Saha SS. Index case of kite string causing neurovascular and tendon injury to ankle is being reported. Indian J Plast Surg 2016;49(01):132-133

4 Nayak BB, Lopamudra M. Functional outcome in digital replantations - a study over a period of 5 years. Int J Contemp Med Res 2019;6(05):E12-E15

\section{Conflict of Interest}

None declared. 